\title{
Corrigendum to: Biparental negotiation or larval begging? Determinant of male provisioning in a burying beetle (Nicrophorus quadripunctatus) (Behaviour 157/8-9 (2020) 719-729, DOI: 10.1163/1568539X-bja10020)
}

\author{
Seizi Suzuki * \\ Department of Ecology and Systematics, Graduate School of Agriculture, Hokkaido \\ University, Kitaku kita 9 Nishi 9,Sapporo 060-8589, Japan \\ *Author's e-mail address: seizis@ res.agr.hokudai.ac.jp
}

Received 9 March 2020; initial decision 19 May 2020; revised 15 June 2020; accepted 18 June 2020

In the above-mentioned article, Figure 3 appeared twice, once as Figure 1, once as Figure 3. The correct Figure 1 is shown below. The author apologises for the oversight.

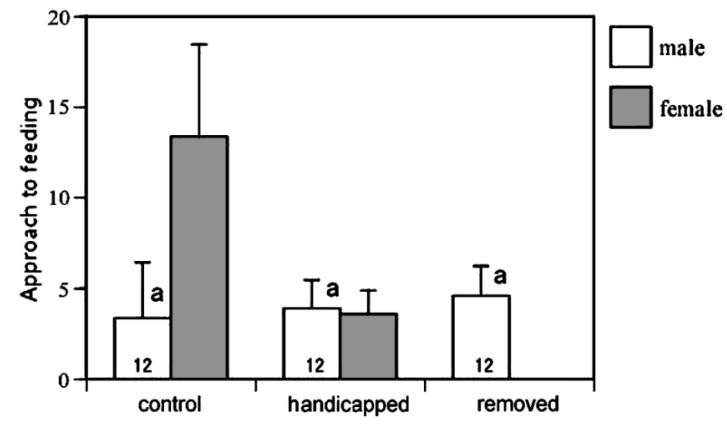

Figure 1. The difference among treatments (female handicapped, female removed, and control) on the number of times that parents approached young to feed in $30 \mathrm{~min}$. Data are presented as mean $+\mathrm{SE}$. The same letter above the bars indicates that the responses are not significantly different (Steel-Dwass test, $p>0.05$ ). 